\title{
Perancangan dan Pengembangan Permainan "Super Sigi" Menggunakan Stencyl Sebagai Media Pengenalan Menyikat Gigi
}

\author{
Yusnia Alfi Syahrin ${ }^{1)}$, Kodrat Iman Satoto ${ }^{2)}$, Kurniawan Teguh Martono ${ }^{2)}$ \\ Program Studi Sistem Komputer Fakultas Teknik Universitas Diponegoro \\ Jalan Prof. Sudharto, Tembalang, Semarang, Indonesia
}

\begin{abstract}
To maintain and preserve healthy teeth is very important to prevent damage inflicted due to ignore. The introduction for maintaining and preserving the healthy teeth since early seems necessary because the damage of teeth which allowed too long would be bad for children later. The introduction about healthy teeth care for children also can use the role of technology nowadays like multimedia. Based on those things, there is an idea to design and build a game application for helping that issue. Through this "Super Sigi" game, hopefully become an instrumentality of a healthy teeth care introduction especially of brushing the teeth for children.

The "Super Sigi" game is made from Stencyl. Stencyl is a toolkit for creating $2 D$ video games that will run on many different mobile and desktop devices. This game developed by the method of Multimedia Development Life Cycle (MDLC) that consists of concept, design, collecting material, assembly, and distribution.

The result of this research is a "Super Sigi" game application that can be a utility for children containing an introduction about how to care the teeth. Based on the black-box testing, the whole function of the menu that is in the game has successfully and run according to each function.
\end{abstract}

Index Terms: Game, Super Sigi, Brushing Teeth, Stencyl, MDLC.

\section{PENDAHULUAN}

\subsection{Latar Belakang}

Peran kemajuan teknologi dalam dunia pendidikan saat ini sangat berpengaruh salah satunya adalah multimedia. Multimedia telah digunakan pada berbagai bidang, seperti bisnis, pendidikan, hiburan, serta berbagai kepentingan umum lainnya. Khusus untuk bidang pendidikan, saat ini multimedia memiliki peranan yang sangat penting, yakni untuk memperkaya dan memajukan proses pembelajaran ${ }^{[10]}$.

Permainan atau game merupakan format multimedia yang biasa digunakan oleh guru dalam pembelajaran khususnya untuk anak-anak. Game adalah salah satu produk teknologi yang dapat digunakan sebagai alternatif media pembelajaran dan mengingat materi belajar ${ }^{[12]}$. Pembelajaran berbasis game lebih disenangi kalangan anak-anak, tanpa menghilangkan esensi ilmu yang ingin disampaikan ${ }^{[6]}$.

Merawat gigi agar tetap bersih dan sehat merupakan hal yang penting dan tidak dapat diabaikan begitu saja. Perawatan gigi sejak dini dinilai sangat penting untuk menghindari proses kerusakan gigi seperti gigi berlubang, keropos, dan pembengkakan pada gusi. Salah satu dampak yang ditimbulkan dari kerusakan gigi pada anak ialah berubahnya bentuk mulut dan tatanan gigi pada saat anak beranjak dewasa nanti. Selain itu, anak juga akan sulit mencerna makanan sehingga proses pertumbuhannya akan terganggu, akibatnya anak akan mudah terserang penyakit ${ }^{[22]}$.

Pengenalan tentang menjaga kesehatan gigi pada anakanak juga dapat memanfaatkan peran multimedia salah satunya melalui game. Berdasarkan hal tersebut, muncul ide untuk memperkenalkan cara merawat kesehatan gigi khususnya menyikat gigi untuk anak-anak melalui permainan "Super Sigi". Dengan adanya permainan ini diharapkan akan dapat mengenalkan kepada anak-anak tentang kebiasaan merawat kesehatan gigi khususnya menyikat gigi.

\subsection{Tujuan}

Tugas akhir ini bertujuan untuk merancang sebuah aplikasi permainan sebagai sarana pengenalan tentang menjaga kesehatan gigi khususnya menyikat gigi untuk anakanak.

\subsection{Batasan Masalah}

Untuk menghindari pembahasan yang meluas, maka dalam tugas akhir ini ditetapkan batasan-batasan masalah sebagai berikut:

a. Permainan dibuat menggunakan Stencyl mulai dari versi 3.0 dan dijalankan dengan menggunakan Adobe Flash.

b. Permainan ini diekspor sebagai Small Web Format (.swf) dan dimainkan secara single player.

c. Permainan dijalankan pada sistem operasi Microsoft Windows 7 dan Microsoft Windows 8.

d. Permainan ini hanya sebagai media pengenalan pentingnya menyikat gigi untuk anak-anak bukan merupakan simulasi cara menyikat gigi.

e. Aplikasi ini hanya bersifat purwarupa.

f. Penelitian ini hanya bertujuan untuk merancang permainan "Super Sigi" dan tidak membahas dampak penggunaan aplikasi tersebut di masyarakat.

\section{LANDASAN TEORI}

\subsection{Permainan (Game)}

permainan (game) adalah sebuah sistem dimana pemainnya terlibat dalam suatu konflik buatan, ditentukan oleh aturan, yang menghasilkan keluaran atau hasil yang dapat diukur. Menurutnya, pada akhir dari sebuah game, seorang pemain akan menang atau kalah atau akan menerima semacam skor numerik ${ }^{[11]}$.

Chris Crawford mendefinisikan istilah game menggunakan runtutan dikotomi pada Gambar $1^{[7]}$. 


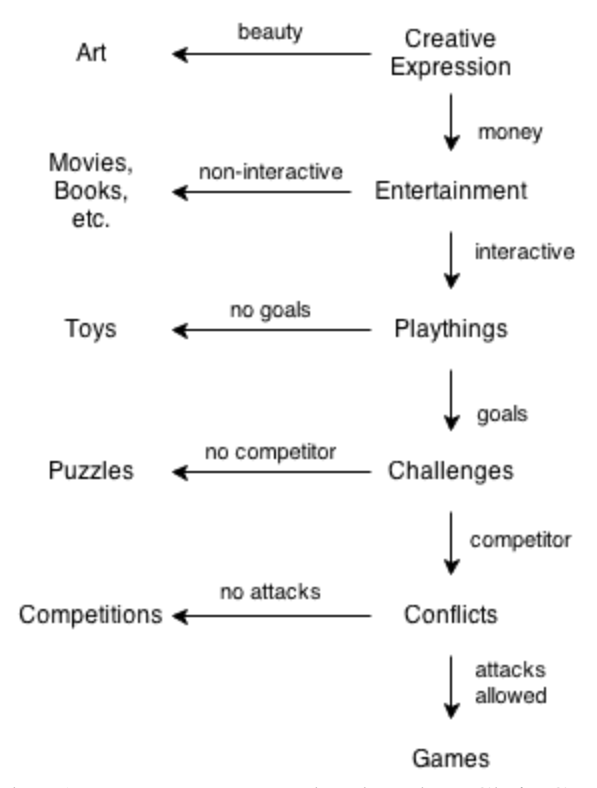

Gambar 1. Perunutan games berdasarkan Chris Crawford

Berdasarkan definisi dari Crawford tentang game dapat diuraikan bahwa game merupakan suatu yang interaktif, berorientasi pada pencapaian goal, agen yang aktif sebagai lawan ataupun player (pemain) lain yang bisa saling berinteraksi satu dengan yang lainnya ${ }^{[12]}$.

\subsection{Multimedia}

Multimedia merupakan kombinasi teks, seni, suara, gambar, animasi dan video yang disampaikan dengan komputer atau dimanipulasi secara digital dan dapat disampaikan dan/atau dikontrol secara interaktif.

Sebuah sistem multimedia dapat digambarkan seperti pada Gambar $2^{[4]}$.

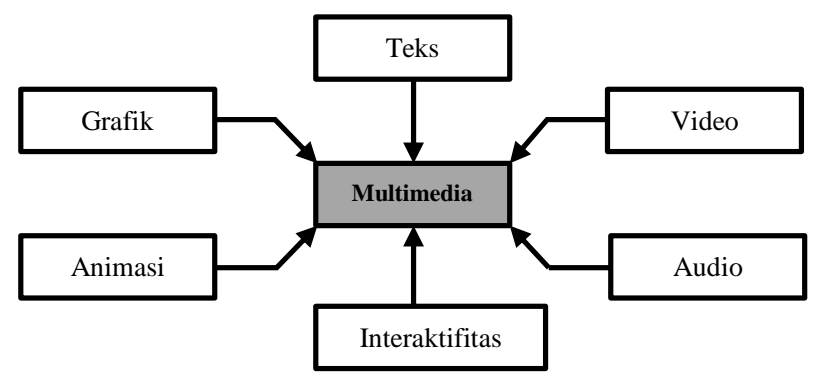

Gambar 2. Gambaran definisi multimedia

\subsection{Media Pembelajaran}

Media merupakan alat saluran komunikasi. Media dapat diibaratkan seperti televisi, diagram, bahan tercetak (printed materials), komputer, dan instruktur. Pembelajaran merupakan suatu kegiatan yang melibatkan seseorang dalam upaya memperoleh pengetahuan, keterampilan dan nilai-nilai positif dengan memanfaatkan berbagai sumber untuk belajar. Pembelajaran dapat melibatkan siswa sebagai pembelajar dan guru sebagai fasilitator. Yang terpenting dalam kegiatan pembelajaran adalah terjadinya proses belajar ${ }^{[14]}$.

\subsection{Pengenalan Menyikat Gigi pada Anak}

Menyikat gigi adalah cara umum yang dianjurkan untuk membersihkan gigi dari berbagai kotoran yang melekat pada permukaan gigi dan gusi ${ }^{[13]}$.

Banyak para ahli berpendapat bahwa menyikat gigi 2 kali sehari sudah cukup yaitu pagi sesudah makan dan malam sebelum tidur. Menggosok gigi setelah makan bertujuan mengangkat sisa-sisa makanan yang menempel di permukaan ataupun di sela-sela gigi dan gusi. Sedangkan menggosok gigi sebelum tidur berguna untuk menahan perkembangbiakan bakteri dalam mulut karena dalam keadaan tidur tidak diproduksi ludah yang berfungsi membersihkan gigi dan mulut secara alami. Untuk itu usahakan gigi betul-betul dalam kondisi bersih sebelum $\operatorname{tidur}^{[3]}$.

\subsection{Stencyl}

Stencyl merupakan suatu toolkit untuk membuat suatu video games 2 dimensi yang berjalan di desktop dan beberapa mobile device yang berbeda. Scene atau level dalam permainan dibuat melalui Scene Designer dengan cara dragand-drop. Instruksi atau logika dari permainan stencyl dapat dibuat menggunakan Stencyl's Gameplay Designer, yaitu sebuah sistem yang memanfaatkan serangkaian blok untuk menciptakan instruksi yang digunakan oleh objek dalam game yang telah dibuat ${ }^{[5]}$.

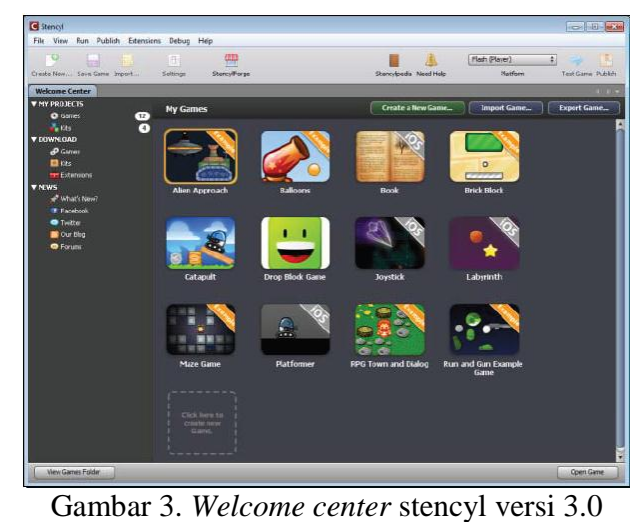

Stencyl dapat diunduh melalui www.stencyl.com. Versi gratis dari stencyl dapat digunakan untuk mengembangkan dan mempublikasikan flash dan HTML5 dan juga dapat digunakan untuk mengembangkan dan menguji permainan untuk komputer desktop dan perangkat mobile. Sedangkan untuk mempublikasikan permainan untuk platform lain selain flash dan HTML5, harus membayar untuk berlangganan tiap tahun agar dapat mengakses fitur tambahan.

Stencyl mendukung berbagai macam platform termasuk web browser, Microsoft Windows, Mac OS X, dan iOS, Android, dan Linux. Game yang dibuat dengan stencyl dapat diekspor ke web melalui Adobe Flash Player, dan untuk komputer pribadi sebagai game executable (.exe), serta ke berbagai perangkat mobile seperti iOS dan aplikasi Android. Mulai versi 3.0, proyek di Stencyl memanfaatkan bahasa pemrograman Haxe dan kerangka permainan OpenFL untuk memungkinkan kefleksibelitasan gaya penciptaan permainan write once, run anywhere. 


\subsection{Adobe Flash}

Adobe Flash (dulu dikenal dengan Macromedia Flash) merupakan platform multimedia yang awalnya dikembangkan oleh Macromedia dan sekarang dikembangkan dan didistribusikan oleh Adobe System. Sejak diperkenalkan pada tahun 1996, Flash menjadi sebuah metode yang populer untuk menambahkan animasi dan interaktivitas pada halaman web. Flash biasanya digunakan untuk membuat animasi, iklan, dan beragam komponen halaman web, untuk mengintegrasikan video ke dalam halaman web, dan saat ini digunakan untuk mengembangkan internet yang "kaya" "[4].

File-file dalam format SWF atau ShockWave Flash, flash movie atau flash games biasanya mempunyai ekstensi .swf dan mungkin menjadi suatu objek dari halaman web, secara khusus dapat dimainkan ada Flash Player yang berdiri sendiri (standalone) atau tergabung dalam projector yang merupakan self-executing konten Flash (dengan ekstensi .exe di Windows atau.$h q x$ di Mac). File flash video mempunyai ekstensi fflv dan digunakan di dalam .swf atau dimainkan sendiri dengan pemutar (player) yang mendukung format tersebut, seperti VLC, QuickTime, atau Windows Media Player dengan tambahan codec tertentu ${ }^{[4]}$.

\subsection{Metodologi Pengembangan Multimedia}

Metodologi yang digunakan adalah Multimedia Development Life Cycle (MDLC) yang bersumber dari Luther dan sudah dimodifikasi oleh Sutopo. Metodologi pengembangan multimedia tersebut terdiri dari enam tahap, yaitu konsep (concept), desain (design), pengumpulan materi (material collecting), pembuatan (assembly), pengujian (testing), dan distribusi (distribution). Keenam tahap ini tidak harus berurutan dalam prakteknya, tahap-tahap tersebut dapat saling bertukar posisi. Meskipun begitu, tahap konsep memang harus menjadi hal yang pertama kali dikerjakan ${ }^{[4]}$. MDLC ditunjukkan pada Gambar 4 berikut.

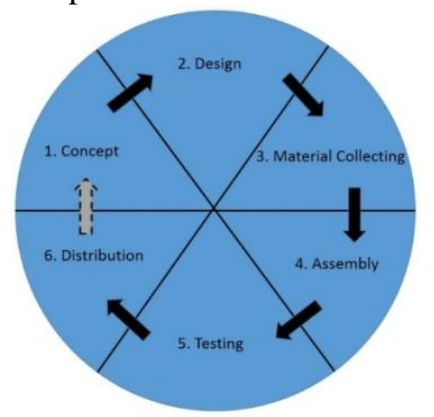

Gambar 4. Tahapan pengembangan multimedia.

\section{PERANCANGAN SISTEM}

\subsection{Konsep}

Permainan "Super Sigi" dibuat bertujuan sebagai media yang berisi tentang pengenalan menyikat gigi bagi anak-anak. Skenario dari permainan "Super Sigi" diantaranya sebagai berikut:

1. Permainan "Super Sigi" terdiri dari 13 halaman yaitu halaman awal, halaman menu utama, halaman transisi pagi, halaman permainan pagi, halaman transisi malam, halaman permainan malam, halaman saat permainan berhasil, halaman saat permainan gagal, halaman petunjuk permainan, halaman pengertian gigi, halaman cara merawat gigi, halaman akibat gigi tidak dirawat, dan halaman credits.

2. Permainan utama terdiri dari 2 scene yaitu saat scene pagi hari dan scene malam hari.

3. Misi dari permainan ini adalah mengumpulkan seluruh makanan dan menghilangkan seluruh kuman dengan cara menembakkan pasta gigi ke arah kuman yang berada pada tiap scene permainan utama.

4. Aturan dalam permainan ini adalah pemain akan diberi batas waktu dan 3 kali kesempatan (nyawa) untuk mengumpulkan seluruh makanan dan menghilangkan seluruh kuman pada tiap scene. Apabila pemain menyentuh kuman atau pemain kehabisan waktu, maka kesempatan akan berkurang dan permainan akan diulang dari awal scene permainan utama.

\subsection{Desain}

Dalam tahap desain ini dibagi menjadi dua, yaitu merancang pembuatan alur permainan melalui diagram alir dan merancang desain tampilan permainan.

Pembuatan bagan perancangan aplikasi menjelaskan permainan secara garis besar. Untuk menjelaskan masing masing bagian dari alur permainan dibuat flowchart.

Diagram alir dari halaman utama ditunjukkan oleh Gambar 5.

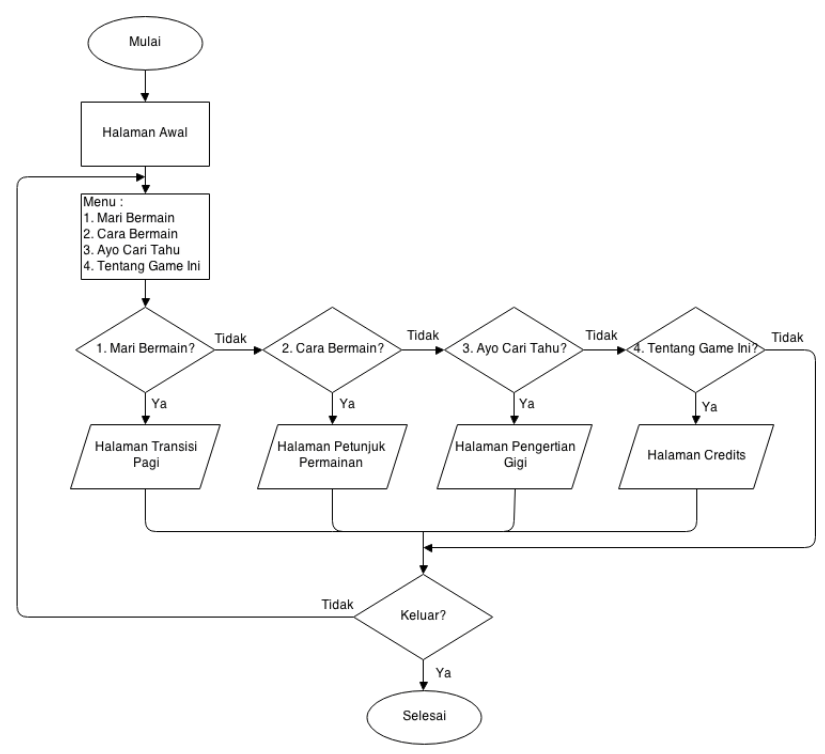

Gambar 5. Diagram alir halaman utama 
Gambar 6 menunjukkan diagram alir pilihan menu mari bermain.

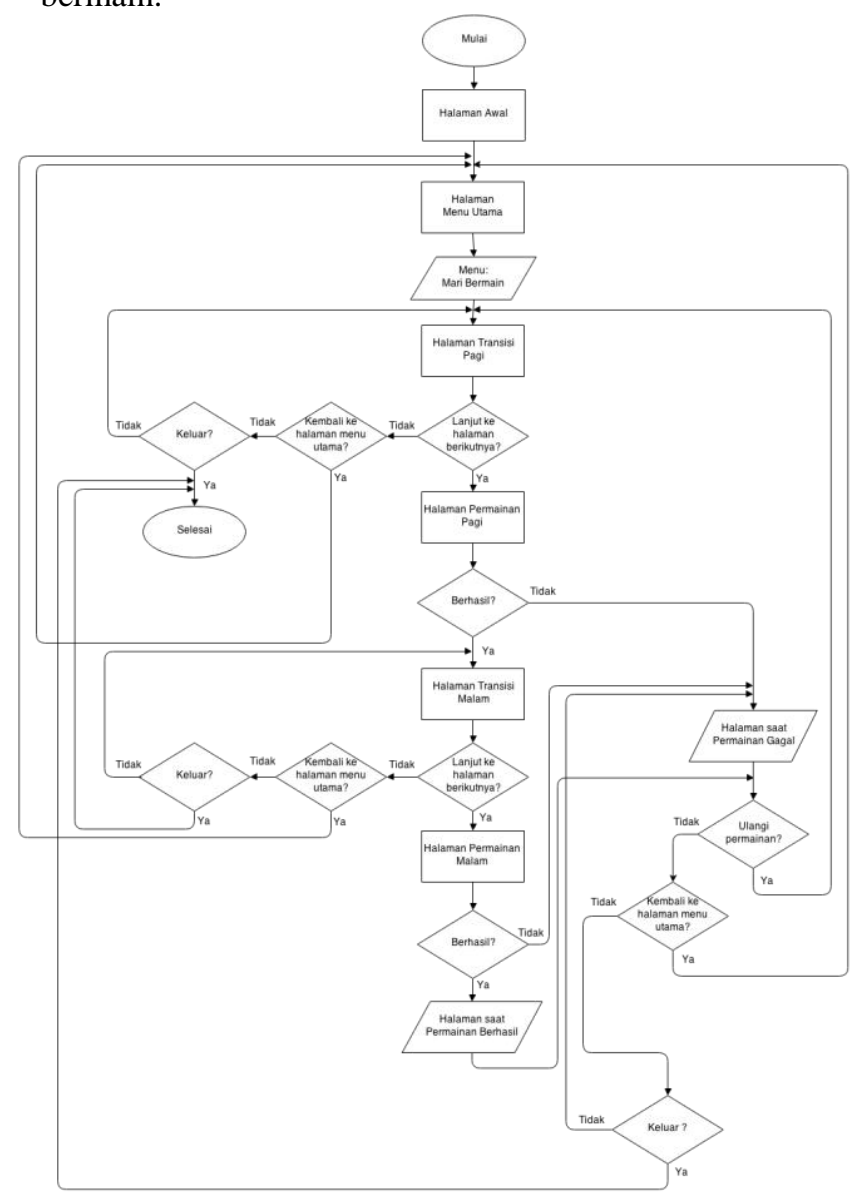

Gambar 6. Diagram alir pilihan menu mari bermain

Diagram alir dari pilihan menu cara bermain ditunjukkan oleh Gambar 7.

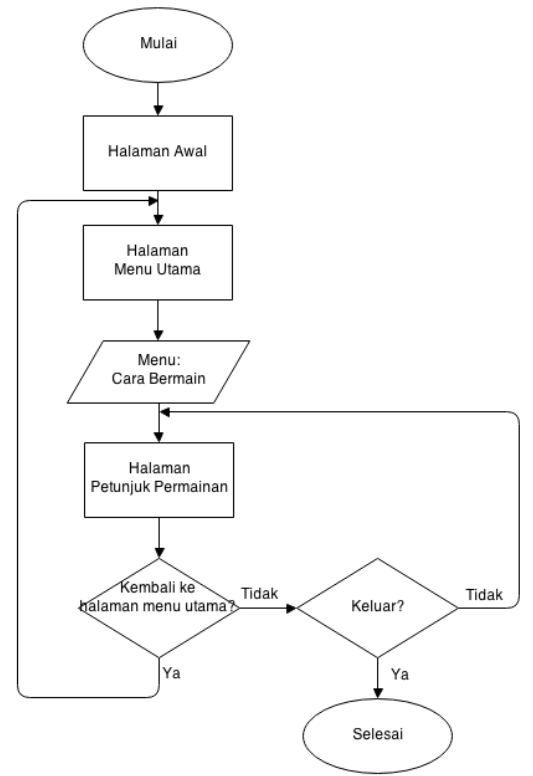

Gambar 7. Diagram alir pilihan menu cara bermain

Diagram alir dari pilihan menu ayo cari tahu ditunjukkan oleh Gambar 8.

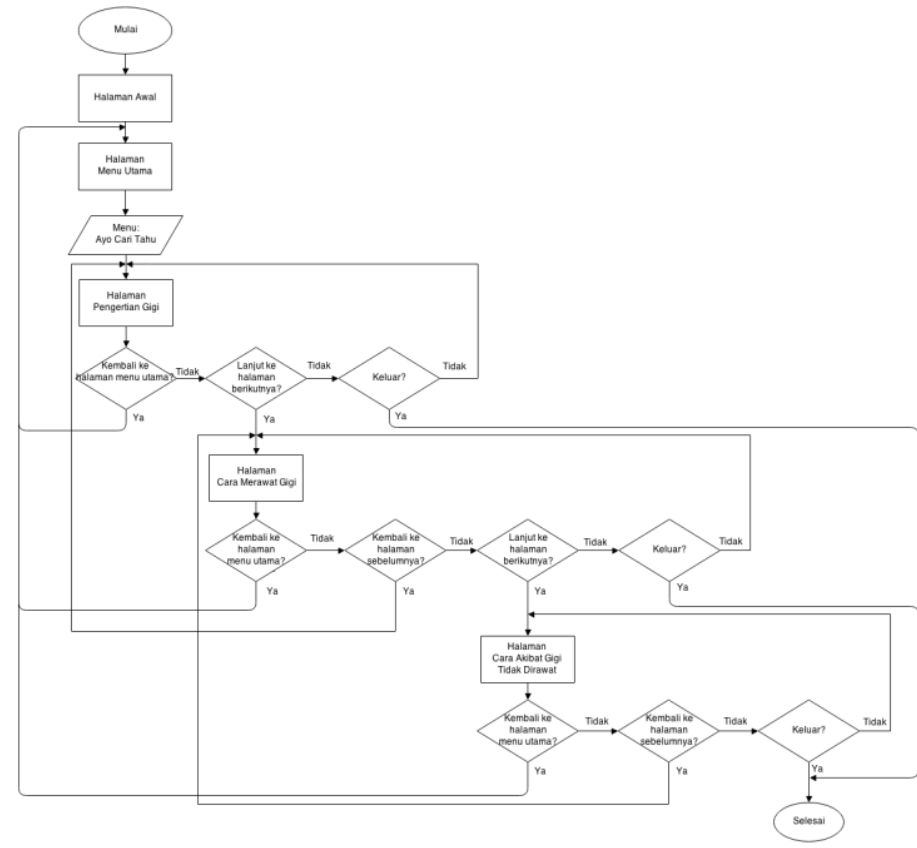

Gambar 8. Diagram alir pilihan menu ayo cari tahu

Setelah dibuat diagram alir untuk mengetahui alur program, selanjutnya dibuat desain tampilan aplikasi. Tampilan rancangan halaman menu utama ditunjukkan oleh Gambar 9.

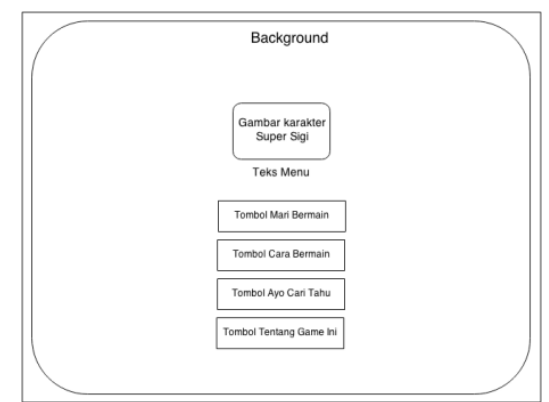

Gambar 9. Rancangan halaman menu utama

Tampilan rancangan halaman permainan pagi ditunjukkan oleh Gambar 10.

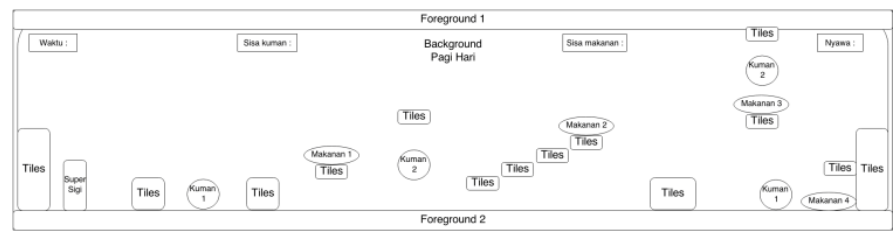

Gambar 10. Rancangan halaman permainan pagi

Tampilan rancangan halaman pengertian gigi ditunjukkan oleh Gambar 11. 


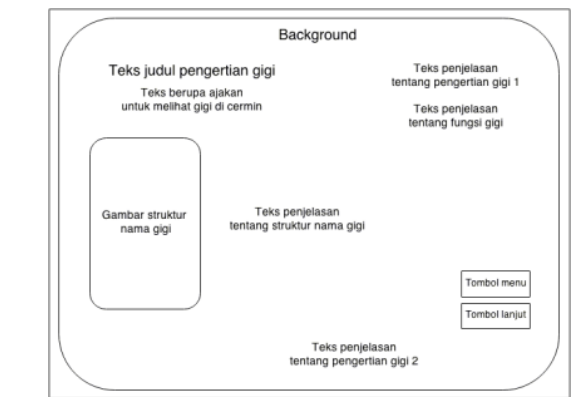

Gambar 11. Rancangan halaman pengertian gigi

\subsection{Pengumpulan Materi}

Dalam tahap ini dilakukan pengumpulan materi yang diperlukan dalam pembuatan permainan "Super Sigi" diantaranya konten - konten tampilan grafik atau gambar serta efek suara yang diunduh dari beberapa sumber yang telah dicantumkan di halaman credits pada permainan "Super Sigi". Selain itu adapun konten materi dari halaman pengertian gigi diambil dari buku sekolah elektronik Ilmu Pengetahuan Alam (IPA) SD kelas 5 terbitan Pusat Perbukuan Departemen Pendidikan Nasional (Depdiknas) tahun 2009 yang diunduh dari http://www.bse.kemdikbud.go.id/. Untuk konten materi beserta gambar cara menyikat gigi dari halaman cara merawat gigi diambil dari buku kesehatan peserta didik terbitan dari kementrian kesehatan Republik Indonesia (RI) yang diunduh dari http://www.gizikia.depkes.go.id/.

\subsection{Pembuatan}

Pada saat membuat permainan "Super Sigi" perangkat keras dan perangkat lunak yang digunakan memiliki spesifikasi sebagai berikut:

a. Perangkat Keras

- Personal Computer (PC) atau Laptop

- 1 buah mouse

- Speaker

b. Perangkat Lunak

- Microsoft Windows 7 Professional

- Stencyl versi 3.0

- Adobe Photoshop CS3

- Corel Draw X4

- Audacity versi 1.2.6

- Adobe Flash Player versi 11

\subsection{Pengujian}

Pada tahap ini dilakukan pengujian dari permainan yang telah dibuat, apakah permainan sudah sesuai dengan perancangan dan kebutuhan atau belum. Dalam pengujian ini dilakukan per menu, bukan setelah semua aplikasi selesai. Hal ini akan mempermudah dalam deteksi kesalahan karena ketika terdapat kesalahan dari suatu menu maka dapat langsung diperbaiki. Pengujian pada pembuatan permainan ini menggunakan pengujian black box testing yang berguna untuk menguji fungsionalitas suatu program yang akan dibahas pada bab selanjutnya.

\subsection{Distribusi}

Hasil program dari permainan akan diekspor menjadi file berekstensi .swf yang dapat dimainkan dengan Adobe Flash Player. File tersebut disalin ke dalam suatu flash memory sehingga nantinya dapat didistribusikan kepada komputer maupun laptop pengguna.

\section{HASIL DAN PEMBAHASAN}

\subsection{Hasil Pembuatan Permainan "Super Sigi"}

Pembuatan permainan diawali dengan membuat resources dari permainan terlebih dahulu antara lain membuat actor types, background, fonts, scenes, sounds, dan tilesets dimana pada stencyl seluruhnya tergabung dalam resources. Agar dapat berjalan sesuai dengan fungsinya masing-masing, resources yang telah dibuat perlu diberi instruksi atau perlakuan (behavior). Pada stencyl, behavior termasuk dalam logic yang terdiri dari actor behavior dan scene behavior.

1. Hasil Tampilan Resources Permainan

- Actor Types

Actor types merupakan tipe aktor yang akan dibuat berupa karakter maupun tombol-tombol yang ada pada permainan ini. Actor types dapat diberi perlakuan atau behavior yang berbeda-beda sehingga dapat berjalan sesuai behavior yang telah diberikan. Ada 34 actor types pada permainan ini. Actor types dalam permainan "Super Sigi" ditunjukkan pada Gambar 12.

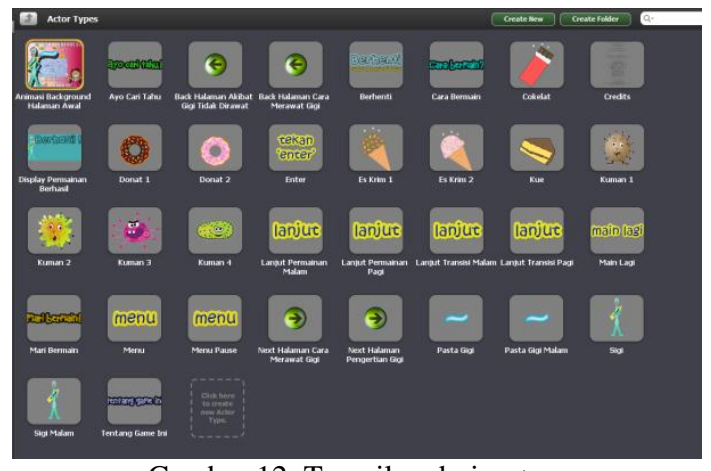

- Scenes

Scenes merupakan halaman atau layout dari permainan yang dibuat. Pada permainan "Super Sigi" terdapat 13 scenes atau halaman. Scenes dalam permainan ini ditunjukkan pada Gambar 13.

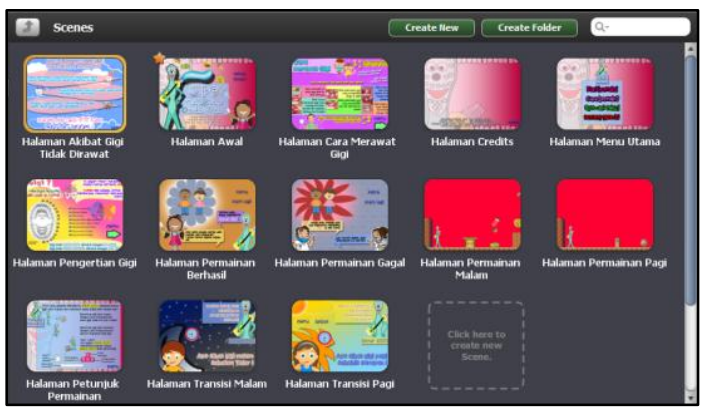

Gambar 13. Tampilan dari scenes

\section{- Actor Behaviors}

Suatu aktor dapat melakukan instruksi apabila diberi perlakuan atau behavior. Dalam permainan ini menggunakan sebanyak 13 behaviors seperti pada Gambar 18.

- Scene Behaviors

Scenes behaviors merupakan behaviors yang dibuat untuk scenes atau halaman permainan. Pada scenes behaviors 
instruksi-instruksi untuk tiap scenes diberikan agar scenes yang telah dibuat dapat berjalan sesuai fungsinya. Terdapat 4 behaviors yang digunakan dalam scenes permainan ini seperti yang ditunjukkan pada Gambar 19.

\section{Hasil Tampilan Halaman Permainan}

Permainan "Super Sigi" memiliki resolusi layar berukuran 640 x 480 piksel. Pada halaman menu utama. Tombol menu utama tersebut antara lain menu 'Mari bermain!', menu 'Cara bermain?', menu 'Ayo cari tahu!', dan menu 'Tentang game ini'. Gambar 14 menunjukkan tampilan halaman menu utama.

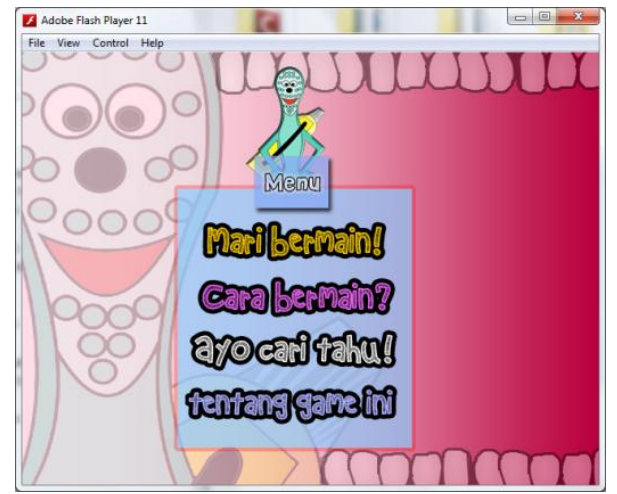

Gambar 14. Tampilan halaman menu utama

Halaman permainan pagi merupakan halaman permainan utama pada permainan "Super Sigi" karena pada halaman ini pengguna dapat memainkan karakter utama dari permainan ini yaitu aktor Super Sigi sehingga pengguna dapat disebut dengan player (pemain). Ukuran dari halaman ini adalah 1920 x 480 piksel. Background dari halaman permainan pagi dibuat dengan warna cerah dengan gambar sinar matahari dan awan-awan seolah-olah pemain berada pada waktu pagi hari seperti yang ditunjukkan pada Gambar 15 .

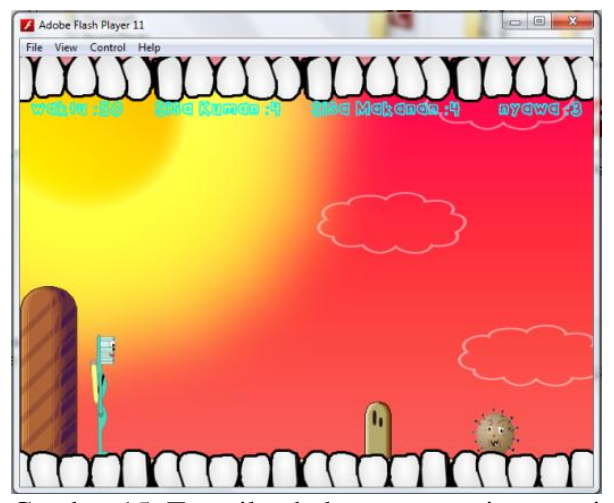

Gambar 15. Tampilan halaman permainan pagi

Pada scene permainan utama ini pemain harus mengumpulkan seluruh makanan dan menghilangkan seluruh kuman dengan cara menembakkan pasta gigi ke arah kuman. Pemain akan diberi batas waktu sebanyak 50 detik dan 3 kali kesempatan (nyawa). Apabila pemain menyentuh kuman atau pemain kehabisan waktu, maka kesempatan akan berkurang dan permainan akan diulang dari awal scene permainan utama.

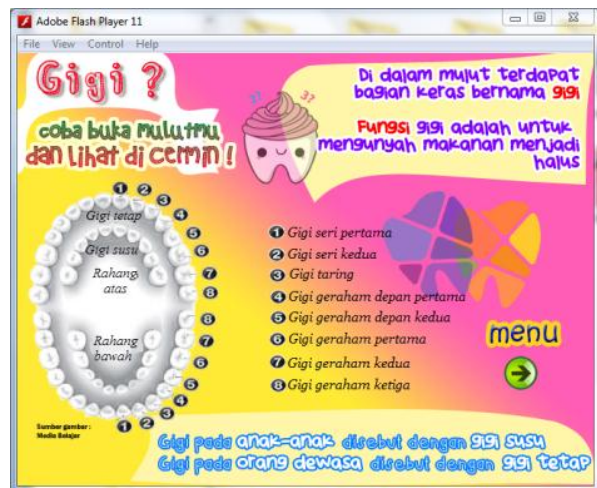

Gambar 16. Tampilan halaman pengertian gigi

Apabila memilih menu 'ayo cari tahu' maka akan tampil halaman pengertian gigi seperti yang ditunjukkan pada Gambar 16.

\subsection{Hasil Pengujian}

Pengujian permainan "Super Sigi" dilakukan dengan menggunakan metode black-box. Pengujian ditekankan pada fungsionalitas dari permainan. Tahap ini berisi serangkaian pengujian fungsi dan tombol pada permainan.

Tabel 1. Pengujian halaman menu utama

\begin{tabular}{|c|c|c|c|}
\hline $\begin{array}{c}\text { Nama } \\
\text { Pengujian } \\
\end{array}$ & $\begin{array}{c}\text { Bentuk } \\
\text { Pengujian }\end{array}$ & $\begin{array}{c}\text { Hasil } \\
\text { yang Diharapkan }\end{array}$ & $\begin{array}{c}\text { Hasil } \\
\text { Pengujian } \\
\end{array}$ \\
\hline $\begin{array}{l}\text { Pengujian } \\
\text { tombol menu } \\
\text { 'mari } \\
\text { bermain!' }\end{array}$ & $\begin{array}{l}\text { Klik tombol } \\
\text { menu 'mari } \\
\text { bermain!' }\end{array}$ & $\begin{array}{l}\text { Tampil halaman } \\
\text { transisi pagi }\end{array}$ & Berhasil \\
\hline $\begin{array}{l}\text { Pengujian } \\
\text { tombol menu } \\
\text { 'cara } \\
\text { bermain?' }\end{array}$ & $\begin{array}{l}\text { Klik tombol } \\
\text { menu 'cara } \\
\text { bermain?' }\end{array}$ & $\begin{array}{l}\text { Tampil halaman } \\
\text { petunjuk permainan }\end{array}$ & Berhasil \\
\hline $\begin{array}{l}\text { Pengujian } \\
\text { tombol menu } \\
\text { 'ayo cari } \\
\text { tahu!' }\end{array}$ & $\begin{array}{l}\text { Klik tombol } \\
\text { menu 'ayo } \\
\text { cari tahu!' }\end{array}$ & $\begin{array}{l}\text { Tampil halaman } \\
\text { pengertian gigi }\end{array}$ & Berhasil \\
\hline $\begin{array}{l}\text { Pengujian } \\
\text { tombol menu } \\
\text { 'tentang } \\
\text { game ini' }\end{array}$ & $\begin{array}{l}\text { Klik tombol } \\
\text { menu } \\
\text { 'tentang } \\
\text { game ini' }\end{array}$ & $\begin{array}{l}\text { Tampil halaman } \\
\text { credits }\end{array}$ & Berhasil \\
\hline
\end{tabular}

Hasil pengujian permainan menggunakan metode blackbox menunjukkan bahwa permainan sudah berjalan sesuai dengan spesifikasi kebutuhan dan skenario permainan. Hal ini ditampilkan oleh seluruh tabel pengujian menunjukkan hasil uji "Berhasil" pada tiap fungsi dan tombol dari permainan. Hal ini berarti bahwa secara fungsional, permainan ini telah menghasilkan keluaran yang diharapkan.

\section{PENUTUP}

\subsection{Kesimpulan}

1. Permainan "Super Sigi" sebagai media pengenalan menyikat gigi untuk anak-anak usia 6 sampai 8 tahun telah berhasil dirancang dan dibangun menggunakan Stencyl dan dapat berjalan dengan ekstensi file .swf.

2. Berdasarkan hasil pengujian permainan menggunakan black-box testing, seluruh fungsi menu yang ada dalam aplikasi permainan telah berhasil dan berjalan sesuai dengan fungsinya masing-masing. 


\subsection{Saran}

1. Permainan diekspor menjadi .exe sehingga komputer yang belum terinstal Adobe Flash Player tetap dapat menggunakannya.

2. Materi cara merawat gigi pada permainan "Super Sigi" dapat ditambahkan video, misalnya seperti menambahkan video simulasi cara menyikat gigi yang baik dan benar.

3. Permainan pada halaman permainan pagi dan halaman permainan malam dapat ditambahkan karakter musuh ataupun variasi-variasi permainan yang lain agar pengguna merasa lebih tertantang dan tidak cepat merasa bosan saat bermain.

\section{DAFTAR PUSTAKA}

[1] Ariani, N. dan Haryanto, D., Pembelajaran Multimedia di Sekolah: Pedoman Pembelajaran Inspiratif, Konstruktif, dan Prospektif, Prestasi Pustakarya, Jakarta, 2010.

[2] Arifin, Lukman., Bermain Lebih Baik daripada Nonton TV, Ziyad Visi Media, 2009.

[3] Ariningrum, Ratih., Beberapa Cara Menjaga Kesehatan Gigi dan Mulut, Hipocrates, Jakarta, 2000.

[4] Binanto, Iwan., Multimedia Digital: Dasar Teori dan Pengembangannya, Andi, Yogyakarta, 2010.

[5] Borkwood, Innes., Learning Stencyl 3.x Game Development Beginner's Guide, Packt Publishing, Brimingham, 2013.

[6] Burhani, Ruslan., Kreator: Pembelajaran Berbasis "Game" Lebih Disenangi Anak, http://antaranews.com/, 20 Juli 2014.

[7] Crawford, Chris., Chris Crawford on Game Design, New Riders Publishing, United State of America, 2003.

[8] Departemen Kesehatan RI, Model Pendayagunaan Dokter Gigi dan Perawat Gigi di Sekolah, Direktorat Kesehatan Gigi, Jakarta, 2003.

[9] Ilyas, Yaslis., Studi Kasus Karies Gigi di Indonesia, Penebar Swadaya, Jakarta, 2001

[10] Nurhadi, Teknologi Multimedia Dalam Pendidikan, http://www.uny.ac.id/, 20 Juli 2014.
[11] Salen, Katie, and Zimmerman, Eric., Rules of Play: Game Design Fundamentals, MIT Press, 2004.

[12] Setyaningsih, R. Yuliana., et al., Game Matematika Untuk Pembelajaran Murid SD, Makalah Proyek Akhir, Institut Teknologi Sepuluh Nopember, Surabaya, 2010.

[13] Sumarti, Hubungan Antara Konsumsi Makanan Kariogenik dan Kebiasaan Menggosok Gigi Dengan Timbulnya Penyakit Karies Gigi Sulung Pada Anak Pra Sekolah Usia 4-6 Tahun di Desa Sekaran Kecamatan Gunungpati Semarang, Skripsi S-1, Program Studi Ilmu Kesehatan Masyarakat, Fakultas Ilmu Keolahragaan Jurusan Ilmu Kesehatan Masyarakat, Universitas Negeri Semarang, 2007.

[14] Susilana, Rudi, dan Riyana, Cepi., Media Pembelajaran: Hakikat, Pengembangan, Pemanfaatan, dan Penilaian, CV. Wacana Prima, 2009.

[15] Sutopo, Ariesto Hadi., Multimedia Interaktif Dengan Flash, Graha Ilmu, Jakarta, 2003.

[16] Suyanto, M., Multimedia: Alat untuk Meningkatkan Keunggulan Bersaing, Andi, Yogyakarta, 2009.

[17] Wuriyanti, Dyahsari, Perbedaan Debris Indeks Antara Menyikat Gigi Secara Mandiri Dengan Menyikat Gigi Dibantu Orang Tua Pada Murid Nol Besar TK Marsudisiwi pengkol Kapling Jepara Tahun 2009, Karya Tulis Ilmiah, Jurusan Kesehatan Gigi Politeknik Kesehatan, Semarang, 2009.

[18] Yudhanto, Adi Prasetyo,. Perancangan Promosi EduGames Melalui Event, Skripsi S-1, Jurusan Desain Komunikasi Visual, Universitas Komputer, Bandung, 2010.

[19] Zeembry, 12 Jurus Pamungkas Animasi Kartun Dengan Flash 8, Elex Media Komputindo, Jakarta, 2006.

[20] --, Deteksi Dini Kelainan, Kunjungi Dokter Gigi 6 Bulan Sekali, http://www.pdpersi.co.id/, 20 Juli 2014.

[21] --, Gigi dan Mulut Sehat untuk Kualitas Hidup yang Lebih Baik pada Hari Kesehatan Gigi Nasional Tahun 2012, http://buk.kemkes.go.id/, 20 Juli 2014.

[22] --, Rawatlah Gigi Sejak Dini, http://issuu.com/haluan/, 20 Juli 2014. 